\title{
Histeroscopia: EI rescate de un recurso hacia el siglo XXI
}

\author{
Jaime Machicado Herrera*
}

La Endoscopia tuvo su comienzo a principios del siglo XIX, cuando Bozzini en 1805, inventó un tubo hueco para observar cavidades humanas, como la nariz, uretra, vagina y recto. La fuente de iluminación era la llama de una vela reflejada en un espejo.

La primera endoscopia satisfactoria fue presentada por Desormeaux en 1853 a la Academia Imperial de Medicina en París, para una endoscopia en uretra y vejiga; desde entonces insinuaba su utilización en el útero. El primer éxito en la histeroscopia lo publica Pantaleoni en el Medical Press and Circular el 14 de julio de 1869, con la extirpación de un pólipo endometrial en una paciente de 60 años.

El precursor de la endoscopia moderna ha sido considerado, Maximilian Nitze, por sus importantes avances en la óptica e iluminación.

En 1907 las innovaciones de Nitze fueron aplicadas a la histeroscopia por Charles Davida. Aplicó la iluminación con una bombilla incandescente introducida dentro del útero por un endoscopio. Selló el extremo distal del tubo con una pieza de cristal, creando de esta forma un típico histeroscopio de contacto.

En los siguientes 50 años, todas las investigaciones y descubrimientos de la histeroscopia estuvieron dirigidos a separar las paredes uterinas, permitiendo una visión panorámica. Varios gases y líquidos fueron usados con este fin.

Cabe destacar los esfuerzos realizados por Rubin en 1925, utilizando dióxido de carbono como medio de distensión. Pero fue Lindemann quien en 1971 redescubrió, refinó y popularizó la histeroscopia panorámica con $\mathrm{CO}_{2}$ y definió los márgenes de seguridad en un flujo de 30 a $50 \mathrm{ml} / \mathrm{minuto}$ y siempre menor de $100 \mathrm{ml} / \mathrm{minuto}$ a una presión de 40 a $80 \mathrm{~mm}$ de $\mathrm{Hg}$ y máxima de $200 \mathrm{~mm} \mathrm{Hg}$.

Los medios líquidos aparecen como una alternativa con los estudios de Gauss en 1934, sobre el comportamiento en la distensión uterina sin paso a nivel peritoneal. Manken en 1968 introduce el polivinilpirolidona, el cual posteriormente es desechado por no ser biodegradable a nivel hepático y por tener un matiz amarillento en solución, que limita y deforma la visualización del endometrio.

En 1970, Edström y Fernström, introducen el dextran, una sustancia de alto peso molecular, como medio de distensión uterina. Debido a la calidad y ventajas del medio, con su uso, aparece la histeroscopia moderna como un procedimiento práctico.

En 1971, Quiñónez y Guerrero, informan sobre los buenos resultados obtenidos con Dextrosa AD 5\%, como medio de distensión y este medio junto con la Solución Salina, entre los híbridos, son en nuestra práctica los de mayor uso.

\footnotetext{
Sociedad Nortesantandereana de Ginecología y Obstetricia.
}

Hamou diseña en 1979 el microhisteroscopio de $4 \mathrm{~mm}$ de diámetro con el cual logra imagen panorámica. Dicho histeroscopio puede utilizarse sin amplificación, o amplificando 20,60 y hasta 150 veces la imagen por contacto, con lo cual se logra visión microscópica del cérvix y paredes uterinas.

La historia de la Histeroscopia en el país, comienza en 1981 con la visita del Dr. Rafael Quiñónez de México, quien vino a Medellín a dictar una conferencia sobre el tema y posteriormente viajó a Bogotá, al Centro Médico Arturo Aparicio, en donde dictó un curso y capacitó a un distinguido grupo de profesionales con quienes realizó la primera Histeroscopia en Colombia.

Posteriormente, los doctores Arturo Aparicio Laserna y Jaime Ferro Camargo, difundieron en el país y en Latinoamérica la práctica de la Histeroscopia y lo anexaron a los programas de postgrado de centros universitarios. Merece destacar por parte del Doctor Aparicio la invención de un electrobisturí para uso endoscópico con el cual se trataron los primeros septos y pólipos uterinos.

Posteriormente, a raíz de una complicación utilizando la bomba de Quiñónez para infusión de medios de distensión uterina, el Doctor Jaime Ferro Camargo, idea los infusores de presión con bolsas plásticas de soluciones líquidas, método más frecuentemente usado por nosotros en la actualidad.

En 1982, el Doctor Israel Díaz Rodríguez, viaja a Chicago y recibe entrenamiento de parte del Doctor Rafael Valle y en la Clínica de la Asunción de Barranquilla inicia el programa de Histeroscopia Diagnóstica.

Cabe destacar el impulso dado por el Doctor Gilberto Martínez y el grupo de ginecólogos, en el Instituto Nacional de Cancerología, en el estudio de la patología tumoral utilizando la microhisteroscopia de contacto desde 1982.

Las técnicas endoscópicas se han convertido en indispensables para la práctica de una obstetricia y ginecología modernas, y tal vez en ninguna especialidad el número y variedad de procedimientos endoscópicos se dan, como en la nuestra. La mayoría de las estructuras anatómicas, así como los procesos del tracto reproductivo femenino, se prestan a este método de exploración y la aplicación de los métodos endoscópicos, cumplen tanto una función diagnóstica como terapéutica de cirugía mayor y menor.

La Histeroscopia como ninguna, ha sufrido en la última década un avance vertiginoso. La implementación del video, el resectoscopio y la utilización de una variada gama de corrientes y Láser, le han dado un impulso definitivo a la difusión de este procedimiento en nuestro país. La implementación de histeroscopios flexibles de pequeño diámetro, ha permitido el paso a la Histeroscopia Oficial o de Consultorio y su utilización como una alternativa adicional en reproducción asistida, complementa aún más su valor como un recurso con grandes expectativas de desarrollo hacia el siglo XXI. 